\title{
NACIÓN, UN CONCEPTO OSCURECIDO POR EL NACIONALISMO Y EL MARKETING
}

\author{
NATION, A CONCEPT DARKENED BY \\ NATIONALISM AND MARKETING
}

Federico Martínez Roda ${ }^{a^{*}}$

Fecha de recepción y aceptación: 27 de octubre de 2020 y 19 de abril de 2021

DOI: https://doi.org/10.46583/scio_2021.20.749

Resumen: A partir del concepto de soberanía formulado por Bodino surgió la idea de la sustitución de la soberanía del monarca por soberanía de la nación que formuló Sieyès. El concepto de nación unido a la soberanía lo alteró Fichte, para quien la nación era previa al logro de la constitución de un Estado. Desde entonces, el nacionalismo, a partir de la construcción de una "identidad", ha utilizado la palabra nación como lo hizo Fichte, y se han propuesto definiciones de dicha palabra que han oscurecido el concepto, a pesar de que para la ONU y el derecho internacional está claro: la nación requiere población, territorio y Estado soberano. El artículo trata también de los tipos de Estado y, finalmente, analiza brevemente el actual panorama de los estudios sobre el nacionalismo, no por su interés filosófico-jurídico, pues en realidad vive de sus propios mitos, sino por ser "la más destructiva fuerza de nuestro tiempo", en frase de I. Berlin, por lo que hay que entenderlo para evitar sus efectos nocivos en el pensamiento y en la vida política.

\footnotetext{
${ }^{a}$ Catedrático Emérito. Universidad Católica de Valencia San Vicente Mártir.

* Correspondencia: Universidad Católica de Valencia San Vicente Mártir. Facultad de Filosofía. Calle Guillem de Castro, 94. 46001 Valencia. España.

E-mail: fj.martinez@ucv.es
} 
Palabras clave: nación, Estado, soberanía, patria, identidad, nacionalismo.

Abstract: From Bodin's conception of the sovereignty arose the idea of replacing the monarchical sovereignty for the national sovereignty declared by Sieyès. The concept of nation connected to sovereignty was modified by Fichte, who claimed that a nation came before the constitution of the state. Ever since, nationalism, from the construction of one "identity", has been using the term nation as Fichte previously had. Other definitions of nation have been proposed, but they have concealed the concept, ignoring that for both the UN and for the international law, a nation required population, territory and a sovereign state. This article also deals with the forms of the state, and finally, it briefly analyses the current prospects of the studies about nationalism, not because of their philosophical interest -since it nourishes itself from its own myths-, but because, as I. Berlin asserted, it is "the most destructive force of our time". Therefore, to avoid its impact, it is necessary to understand it.

Keywords: nation, State, sovereignty, homeland, identity, nationalism.

Resulta verdaderamente sorprendente que, en una situación mundial de un avance tecnológico sin precedentes, consecuencia del rigor metodológico en el conocimiento científico-experimental, las ciencias sociales se vean, a veces, en entredicho porque no consiguen ni siquiera que se acepten o se reconozcan ni los conceptos de uso común. De esta manera resulta muy difícil construir un discurso coherente, porque, al no aceptarse un significado unívoco de ciertas palabras que sí lo tienen, es imposible el uso del metalenguaje que exige el conocimiento científico-social, ya que el discurso político cotidiano puede desvirtuarlo.

Una de esas palabras que, especialmente en España ${ }^{1}$, se utiliza sin rigor en su contenido semántico es nación, a pesar de que el Diccionario de la

${ }^{1}$ Como consecuencia de esta preocupación, J. Álvarez Junco enumera una serie de definiciones en su trabajo incluido en J. Álvarez Junco, F. Requejo y J. Beramendi (2005). El nombre de la cosa: debate sobre el término "nación” y otros conceptos relacionados, Madrid, Centro de Estudios Políticos y Constitucionales. Prueba del escaso éxito de su propósito, años después (2017) publicó en solitario la obra Dioses útiles: naciones y nacionalismos (Barcelona: Galaxia Gutenberg), en la que continúa 
Real Academia Española es claro: "Conjunto de habitantes de un país regido por el mismo gobierno". Efectivamente, esta definición, aunque no los cita textualmente, recoge los tres componentes del concepto que se acepta en las relaciones internacionales y en los organismos internacionales: población, territorio y Estado. Sin embargo, a continuación, el mencionado diccionario se ve obligado a recoger otro significado que, en cierto modo, desvirtúa el formulado previamente con un concepto que contradice el anterior: "Conjunto de personas de un mismo origen étnico y que generalmente hablan un mismo idioma y tienen una tradición común"2.

En realidad, esta contradicción es consecuencia de las dos grandes fuentes en la creación del concepto nación: la francesa y la alemana. Sin embargo, la filosofía política y la politología deben profundizar más en este concepto dada su importancia y la problemática que se suscita si no se quiere abordar con claridad, y lo primero que surge para una definición correcta es relacionarlo con el concepto de soberanía.

\section{§1. EL CONCEPTO DE SOBERANÍA}

Desde que Platón (427-347 a. C.) planteó la problemática de la gobernación de la polis hasta que Jean Bodin (1530-1596) formuló el concepto de soberanía pasaron casi dos mil años. Entre el siglo IV a. C. y el siglo XVI se debatió sobre la auctoritas y la potestas, especialmente en Roma, y se planteó la cuestión de si había o no plenitudo potestatis, sobre todo en la Baja Edad Media; pero hubo que esperar a Jean Bodin, al que en español se le llama tradicionalmente Bodino, para que se formulara el concepto de soberanía.

abogando por la claridad en los conceptos, aunque con escepticismo, pues considera "que en estos terrenos los conceptos son ambiguos", y sigue a John L. Austin, autor de Cómo hacer cosas con las palabras (Barcelona: Paidós, 1988). También participa de esta preocupación Félix Ovejero, que en su obra de 2016 La seducción de la frontera. Nacionalismo e izquierda reaccionaria (Barcelona: Ed. Montesinos) aboga por esa misma claridad en los conceptos, aunque considera que ese escepticismo, es decir, la confusión terminológica, permite a los nacionalismos sacar una ventaja que no están dispuestos a perder. Este artículo se suma a esta misma preocupación, con la esperanza de ser útil a las ciencias sociales y al debate político.

2 En la actualización de 2019 ha desaparecido la palabra "étnico". 
En cierto modo, se puede considerar a Bodino como un humanista tardío, aunque con muchas coincidencias con Aristóteles y con la escolástica, especialmente al considerar que la unidad social natural primaria es la familia y que el Estado, o si se quiere la sociedad política, es una entidad secundaria o derivada. De ahí que el derecho de propiedad sea un derecho natural de la familia, mientras que en el ámbito de lo político no se posee la propiedad sino la soberanía. Y aquí está la novedad, en el concepto de soberanía, que Bodino define como "el poder supremo entre ciudadanos y súbditos no limitado por la ley". Al ser un poder supremo, la soberanía se caracteriza por ser inalienable, indivisible y absoluta ${ }^{3}$.

Bodino no aclara qué es lo que confiere la soberanía legítima pero, a partir de su formulación en ese momento histórico, su teoría de la soberanía fue aplicable a cualquier forma de gobierno: un rey podía ser el depositario de la soberanía, pero una asamblea también podía tener poder soberano. En conclusión, la soberanía tiene las tres características mencionadas que Sáenz-Díez explica de este modo:

Es inalienable porque no puede dejar de ser perpetua por esencia. Desde luego que pueden delegarse funciones y poderes pero el poder soberano permanece. Es indivisible, en el sentido de que el poder soberano es uno por definición. La soberanía no puede ser parcelada. Es absoluta, ya que las decisiones del poder soberano no dependen de las decisiones de ningún otro poder. El soberano no está limitado por la ley y no puede limitar por ley su soberanía, mientras siga siendo soberano, pues la ley es creación del soberano (Sáenz-Díez, 1994: 73).

\section{§2. De La SOBERANÍA A La NACIÓN}

Sin el concepto de soberanía no se puede entender el surgimiento del concepto de nación, en su acepción contemporánea tanto en el ámbito politológico como en el jurídico. Ya se ha dicho que el poder soberano lo puede ostentar o una persona o una colectividad, incluso un parlamento, y fue también en Francia donde Emmanuel-Joseph Sieyès (1748-1836) relacionó los conceptos soberanía y pueblo, o Tercer Estado, con lo que configuró

\footnotetext{
${ }^{3}$ J. Bodino (1986). Los Seis Libros de la República. Madrid: Tecnos.
} 
el concepto de nación. Al convocarse los Estados Generales, el ministro de Luis XVI Loménie de Brienne (1727-1794) invitó a las personas instruidas de Francia a que enviasen memoriales para preparar las reuniones parlamentarias que se iban a celebrar a partir del primero de mayo de 1789 . Como respuesta a esta petición -lo que le libró de que su escrito fuera censurado o condenado-, Sieyès remitió, en enero de 1789, su famoso opúsculo Qu'est-ce que le Tiers-État?, en el que da la siguiente respuesta a la pregunta del título: el Tercer Estado es "todo", lo que significa, conforme titula al capítulo 1, que el "Tercer Estado es una nación completa"4.

A continuación, Sieyès se prodiga en explicaciones y aclaraciones en relación con afirmaciones tan contundentes, pero el objetivo ya estaba conseguido: "se impone la idea de nación, contra el principio monárquico, como fundamento de una nueva legitimidad comprometida no con el príncipe, sino con el pueblo" (Ruiz Ramírez, 1990: 88). A esta nueva legitimidad se le llamó "soberanía nacional". Andrés-Gallego lo resume de este modo:

Con Sieyès, al monopolizar el nombre nación para el Estado que era fruto de la voluntad general, se dio un paso gigantesco en el pensamiento político: sencillamente se eliminó la posibilidad de que en el marco de un mismo Estado convivieran naciones diferentes (Andrés-Gallego, 2012: 29).

Este nuevo concepto impregnó al Nuevo Régimen, de modo que en las constituciones que se aprobaron a lo largo del siglo XIX en Europa y América se identifica la nación conforme la había definido Sieyès, como "cuerpo de personas asociadas que viven bajo una ley común” (Sáenz-Díez, 1994: 162). Ley común que establece el Tercer Estado (el pueblo), que es la "nación completa". No obstante, Ramón Maiz ha matizado lo siguiente:

Si en un primer momento, en ¿Qué es el Tercer estado?, Sieyès emplea "nación" y "pueblo" como sinónimos, posteriormente, sin embargo, procederá a su diferenciación, reservando en lo sucesivo el término nación para designar al titular de la soberanía $\mathrm{y}$, por tanto, del poder constituyente, y el de "pueblo" para referirse a uno de los dos polos

${ }^{4}$ E. J. Sieyès: Qu'est-ce que le Tiers état?. Disponible en: <www.leboucher.com>.

SCIO. Revista de Filosofia, n. ${ }^{\circ} 20$, Julio de 2021, 185-216, ISSN: 1887-9853 
nacidos de la aparición del Estado constitucional, gobernantes y gobernados, esto es, los ciudadanos ${ }^{5}$.

En cualquier caso, el nuevo concepto filosófico-jurídico de nación surgido a finales del siglo XVIII había roto "completamente con el concepto de nación vigente hasta entonces" (Andrés-Gallego, 2012: 29), que consistía en la adscripción geográfica de las personas a un territorio que no necesariamente correspondía con una entidad política, de hecho, en América se hablaba de las "naciones indígenas", y en las universidades europeas se agrupaban a los estudiantes por "naciones", es decir, por sus lugares de nacimiento, no por los reinos a los que pertenecían. Todo cambiará a partir de este momento: la definición filosófico-jurídica de nación irá acompañada de los tres elementos que la configuran: la población (cuerpo de personas), el territorio (donde están asociadas) y el Estado (que establece esa ley común). Así surgió la simbiosis entre los conceptos de nación y Estado, puesto que sin Estado puede haber pueblo, puede haber territorio, pero no hay nación. Según Ferrando Badía (1926-2007):

La filosofía política de la Revolución francesa ponía el acento sobre el principio de la igualdad de los ciudadanos. De ahí que la centralización apareciese como el medio de eliminar privilegios. La afirmación de la unidad y de la indivisibilidad de la nación (...) la colocó como soberana (Ferrando, 1975: 9-10).

De ahí que Edgar Morin afirmara que "el Estado-nación es, a la vez, creación y creador de la Europa moderna”(Morin, 1993: 451), lo que significa que la Revolución francesa cambió el paradigma político y tuvo una influencia decisiva en el devenir de los países europeos y, después, de todo el mundo; pero este cambio de paradigma se produjo tanto por asunción de las ideas entonces revolucionarias como por reacción a la invasión francesa llevada a cabo por las tropas napoleónicas, teóricas portadoras de esas ideas.

${ }^{5}$ R. Maiz Suárez: < https://revolution-francaise.net/2007/07/09/139-idee-nation-chez-sieyes >. 


\section{§3. De Fichte a Renan}

Precisamente, el concepto de nación surgido en Francia, que fue incorporado en la Constitución de $1791^{6}$, iba a sufrir una importante enmienda en uno de los territorios ocupados por el Ejército imperial de Napoleón Bonaparte (1769-1821). Probablemente, en un primer momento, contribuyeron dos circunstancias muy diferentes entre sí, que confluyeron en esa coyuntura. La primera fue la influencia de Herder, que sentó las bases filosóficas del idealismo alemán; y la segunda, la frustración generalizada tras la derrota sufrida por el Ejército prusiano en Jena, el 14 de octubre de 1806, de cuya universidad había sido profesor Johann G. Fichte (1762-1814), y cuya consecuencia inmediata fue la ocupación de Berlín por las tropas francesas, con la consiguiente huida de la familia real prusiana a Rusia. El tratado de Tilsit, el 7 de julio de 1807, significa la retirada de Rusia y Prusia de la guerra contra Napoleón, lo que fortalece su posición en Europa; pero también supone un duro golpe para Prusia porque debe pagar sanciones y, sobre todo, se ve obligada a renunciar a casi la mitad de su territorio en beneficio de la Confederación Germánica, establecida por Napoleón en sustitución del Sacro Imperio Romano Germánico dentro de su "sistema" para Europa".

En este ambiente de derrota, del 15 de diciembre de 1807 al 20 de marzo de 1808 , Fichte pronunció sus catorce conferencias en la capital del reino vencido, donde dos años después, en 1810, se creaba la Universidad de Berlín $^{8}$. Las conferencias se publicaron poco después del 2 de mayo, lo que permitió a Fichte dedicar su nuevo libro, titulado Renden an die deutsche Nation (Discursos a la nación alemana), a los héroes españoles que se levantaron contra el ejército francés invasor ${ }^{9}$.

${ }^{6}$ El título III, en su artículo 1. ${ }^{\circ}$, la Constitución francesa de 3 de septiembre de 1791 dice: «La soberanía es una, indivisible, inalienable e imprescriptible. Pertenece a la nación; ningún sector del pueblo, ni individuo, puede atribuirse su ejercicio»».

${ }^{7}$ J. Pabón (1944). Las ideas y el sistema napoleónicos. Madrid: Instituto de Estudios Políticos.

${ }^{8}$ W. von Humboldt (1769-1859) fue comisionado para su erección. Se convirtió en una universidad de referencia en materia científica, pero también en el centro principal de difusión del nacionalismo alemán, donde fue contratado J. G. Fichte.

${ }^{9}$ Véase la reciente edición en español J. G. Fichte (2016). Discursos a la nación alemana. Madrid: Tecnos. 
Fichte analizó la Revolución francesa y llegó a la conclusión de que había degenerado en un "imperialismo personalizado en Napoleón" (Villacañas, 1991: 170). El paso siguiente fue la concepción de la guerra prusiana contra Francia, que se reanudó en 1810, en términos de guerra "nacional" que debía arrastrar a ella a todo el pueblo alemán, a toda la "nación" alemana. Al encontrarse dividida Alemania en 38 Estados, 39 si se añadía Austria, reorganizados por Napoleón, que incluso crea la Confederación Germánica, la herramienta para lograr la unión política de Alemania en un Estado es, según Fichte, la educación. De hecho, de los catorce discursos cinco tienen carácter eminentemente pedagógico, aunque tres tratan exclusivamente de las características del pueblo alemán. Para Fichte, la "nación alemana" ya existía porque la configuraba el formar parte de la misma etnia y el hablar la misma lengua. Es decir, la nación no la constituía el Estado (vivir bajo una misma ley o una constitución, en expresión de Sieyès), sino una serie de elementos objetivos previos al propio Estado, en concreto, la etnia, la lengua y la costumbre o tradición jurídica que forma el "espíritu del pueblo" (volksgeist), el "espíritu nacional".

Desde el punto de vista filosófico, cuando Johann G. Herder (1744-1803) afirma que "cada nación habla, por consiguiente, según piensa, y piensa según habla, pues no podemos pensar sin palabras" (Herder, 1877: 18) influye directamente en Fichte, que recogerá esta idea en su integridad, con lo que "las ideas universalistas de la Ilustración radical se traspasaron a la particularidad de la nación" (Villacañas, 1991: 170). No obstante, "el nacionalismo de Fichte no atenta contra las consignas ilustradas, revolucionarias y democráticas. Su peligrosidad reside en que se siente legitimado en su pretensión de monopolizarlas" (Villacañas, 1991: 162).

Los efectos de las ideas de Fichte en la afirmación de la existencia de una nación, en este caso la alemana, por razones objetivas como la etnia y la lengua, lograron que, finalmente, se formara el Estado nacional alemán, pero sus propios principios nacionalistas condujeron al desmembramiento del Imperio austrohúngaro en 1918. A lo largo del siglo xIX los movimientos nacionalistas utilizaron de Fichte sus teorías en relación con la palabra nación. En este sentido, fue un precursor porque se dirige a la "nación alemana", una nación que según el concepto formulado en Francia pocos años antes no existía. Sí había una colectividad germanófona y un territorio en el que era mayoritaria, pero 
había desaparecido el Imperio, el Sacro Imperio Romano-Germánico del que era káiser el archiduque de Austria, de la dinastía Habsburgo, desde el siglo Xv, que además no era propiamente un Estado. Aunque se acepte que la colectividad germanófona era el "pueblo alemán" y que vivía en un determinado territorio, todavía le faltaba el Estado para que hubiera nación alemana; pero Fichte y demás ideólogos del nacionalismo alemán lograron hacer creer que su concepto de nación, sin Estado, era correcto y por eso se afanaron en conseguirlo.

La palabra nación se convirtió en un talismán de los nacionalistas en aquellos lugares donde unos ideólogos consideraban que un pueblo asentado en un territorio, integrado en otro mayor, debía tener un Estado independiente, incluso en ocasiones aunque no existiera ese pueblo diferenciado. Si no las había, se provocaban diferencias, reales o supuestas, para que, a partir de esas diferencias, estuviera justificada la exigencia de un estado independiente del que hablaban los nacionalistas. En 1851, Pasquale Mancini (1817-1888) definía la nación ante sus oyentes de la Universidad de Turín de tal modo que parecía una réplica de Fichte, y por supuesto se olvidaba del componente principal y decisivo que define la nación según la doctrina francesa: el Estado soberano. Decía así: "La nación es una sociedad natural de hombres, de unidad de territorio, de costumbres, de lengua, una comunidad de vida y conciencia social"10. El "concepto nacionalista de nación" (Míguez, 2012: 9) traspasaba el ámbito alemán y oscurecía el significado del significante.

El concepto francés y el alemán de la palabra nación chocaron en 1870 . Las tensiones acumuladas entre el II Imperio francés, encabezado por Napoleón III, y la Prusia de Bismarck (1815-1898) tuvieron como resultado una guerra que se decidió con una victoria aplastante del Ejército prusiano en Sedán (1870), aunque el Tratado de Frankfurt se firmara al año siguiente, el 10 de mayo de 1871. Además de indemnizaciones económicas, el tratado disponía la cesión a Alemania de Alsacia y el noreste de Lorena. Territorios que formaban parte de Francia, pero los habitantes de las dos regiones todavía conservaban la lengua alemana. Este hecho resultaba definitivo para la

${ }^{10}$ P. S. Mancini (1985). Sobre la nacionalidad. Madrid: Tecnos. En realidad, bajo ese título se publica traducido su Discurso de inauguración de la cátedra de Derecho Internacional de la Universidad de Turín, de 22 de enero de 1851, que versó sobre los conceptos nación y nacionalidad y sus efectos jurídicos. 
concepción de nación que Bismarck había heredado del idealismo alemán; en consecuencia, ambas regiones debían formar parte de la nación alemana que se constituía como II Reich. No era necesario tener en cuenta la voluntad de pertenencia de sus habitantes porque "objetivamente" eran alemanes.

De ahí que, pocos años después de la incorporación de Alsacia y Lorena a Alemania como culminación de su unificación, en la conocida conferencia que impartió en la Sorbona, el 11 de marzo de 1882, Ernest Renan (18231892) se preguntara qué es una nación, y así la tituló.

Buen conocedor de la historia, repite varias veces que las naciones se han formado por la fusión de las gentes que la componen, fusión que, en ocasiones ha venido acompañada de violencia o arbitrariedad, incluso de algún error histórico. Llegará a decir que "la gran realeza francesa había sido tan altamente nacional que, inmediatamente después de su caída, la nación ha podido mantenerse sin ella" 11 pero con carácter general; al final "la esencia de una nación consiste en que todos los individuos tengan muchas cosas en común y también en que todos hayan olvidado muchas cosas"; en consecuencia "la nación moderna es, pues, un resultado histórico producido por una serie de hechos que convergen en el mismo sentido" (Renan, 1882: 4).

Argumenta en contra de que la nación esté definida por cuestiones "objetivas" como la pertenencia a una misma etnia o por la de ser hablante de la misma lengua, por los intereses, por la afinidad religiosa, por la geografía o por las necesidades militares (Renan, 1882: 10) y finalmente propone la conclusión siguiente:

Una nación es, pues, una gran solidaridad, constituida por el sentimiento de los sacrificios que se ha hecho y de aquellos que todavía se está dispuesto a hacer. Supone un pasado; sin embargo, se resume en el presente por un hecho tangible: el consentimiento, el deseo claramente expresado de continuar la vida común (...) El voto de las naciones es, en definitiva, el único criterio legítimo, aquel al cual siempre es necesario volver (Renan, 1882: 11).

${ }^{11}$ E. Renan (1882). Qu' est-ce qu'une nation? Existen dos traducciones recomendables: ¿Qué es una nación?, con estudio preliminar de R. Fernández-Carvajal, Madrid: Instituto de Estudios Políticos, del año 1957; y ¿Qué es una nación?, Madrid: Alianza Ed., de 1987. 
Renan ha retomado el concepto de soberanía nacional, pues, aunque la monarquía de los Capeto, de los Valois y de los Borbón fuera la que delimitó territorialmente Francia, es decir, aunque la corona francesa ejerciera su soberanía para crear la nación, "el voto es el único criterio legítimo" para conservarla, esto es, reafirma que el soberano es el conjunto del pueblo, como ya había manifestado Sieyès casi cien años antes.

\section{§4. Tipos De Estado y sujeto CONSTituyente}

Durante la época contemporánea, después de la aparición del concepto de nación, surgieron en el mundo cada vez más naciones, es decir, pueblos que viven en un territorio y se organizaban bajo la forma política del Estado. De hecho, se ha pasado de menos de cincuenta estados reconocidos a principios del siglo XIX a doscientos en la actualidad, aunque en la ONU hay 193 ingresados. Pero la propia dinámica interna de la constitución de estos Estados ha llevado a que, según Carré de Malberg (1861-1935), se puedan clasificar en tres tipos de Estado $^{12}$ : unitario, federal y confederal.

Cada uno de estos tipos responde, como se ha dicho, a la dinámica interna de su constitución. Aquellos Estados cuyos límites territoriales fueron configurados por una corona, y en los que el pueblo sustituyó la soberanía del rey por la soberanía de la nación, constituyeron Estados unitarios. Los ejemplos más claros son Francia y España, que en sus respectivas constituciones de 1791 y 1812 trasladan la soberanía real al pueblo o nación. En consecuencia, al haber un único sujeto constituyente, el Estado que se crea suele ser un Estado unitario. En las demás monarquías europeas se extendió el concepto y en Holanda, Suecia, Dinamarca se redactaron constituciones que, a la vez de trasladar la soberanía del monarca a la nación, establecían el concepto de que "el rey reina pero no gobierna"13.

${ }^{12}$ R. Carré de Malberg (1920). Contribution à la théorie générale de l'État, 2 vols., París: CNRS Éditions. Reeditada en 2003 por la Editorial Dalloz. Una traducción anterior a la reedición, de 1998, lleva por título: Teoría general del Estado. México: Fondo de Cultura Económica.

${ }^{13}$ B. Constant, (1989). Escritos políticos. Madrid: Centro de Estudios Políticos y Constitucionales. 
Las descolonizaciones de la segunda mitad del siglo xx también encontraron en los distintos territorios gobernados por metrópolis europeas sujetos constituyentes únicos. Uno de los primeros acuerdos que tomó la OUA (Organización para la Unidad Africana) fue la intangibilidad de las fronteras ${ }^{14}$. De ahí que, al obtener la independencia, también se convirtieran en sujetos constituyentes los pueblos que se encontraban dentro de esas fronteras, aunque en muchos casos se mantenían estructuras tribales que impedían la necesaria cohesión para formar la nación, pero se actuó como si la hubiera, a pesar de que en ocasiones había tribus divididas por las fronteras coloniales. Por consiguiente, jurídicamente se siguió el mismo proceso que en las grandes monarquías europeas, aunque la situación social era totalmente diferente, porque las coronas europeas con el paso del tiempo habían incrementado los vínculos entre los habitantes de sus respectivos reinos, lo que llevó a que en sus parlamentos se formulara el concepto de soberanía nacional, mientras que, en África, los nuevos Estados independientes se creaban en territorios cuya población no tenía conciencia de pertenecer al mismo pueblo ${ }^{15}$. En cualquier caso, predominó en ambos casos la constitución de Estados unitarios. Normalmente, en el Estado unitario se establecía una estructura política centralizada.

Los sujetos constituyentes, en el Estado federal y en el Estado confederal, son los pueblos soberanos correspondientes a cada uno de los territorios que se incorporan a dicho Estado. Los Estados Unidos de América son el ejemplo paradigmático de federación o Estado federal, aunque la definición de federal quedó consolidada tras la victoria del norte contra los "confederados del Sur", en la Guerra de Secesión (1861-1865). Se había producido un proceso de incorporación paulatino por Estados que, si se consideraba que podían dejar de estar unidos, serían todos ellos un Estado confederal o confederación; mientras que, si una vez incorporados al nuevo Estado se renunciaba a la posibilidad de recobrar la independencia, estarían en un Estado federal. Cuando las trece colonias se independizaron y aprobaron su Constitución no se había definido si el Estado independiente era una federación o una confederación, y el presidente

${ }^{14}$ Se puede consultar el texto íntegro de las primeras resoluciones aprobadas por la Asamblea de la OUA en: <http://www.au.int/en/sites/default/files/ASSEMBLY_EN_17_21_JULY_1964_ASSEMBLY_HEADS_STATE_GOVERNMENT_FIRST_ORDINARY_SESSION.pdf $>$.

${ }^{15}$ F. Châtelet et al. (2006). Historia dè pensamiento político. Madrid: Tecnos. 
Lincoln y los Estados del norte interpretaron la Constitución en clave federal; mientras que los del sur lo hicieron en clave confederal. Al vencer los del norte, la Constitución se interpreta en clave federal y los nuevos Estados, que se incorporaron después de la guerra civil estadounidense, no pueden separarse, pues han ingresado inequívocamente en una federación o Estado federal.

En realidad, el Estado confederal, que consiste en que los sujetos constituyentes son los pueblos soberanos de cada uno de los estados que se unen pero pueden separarse si así lo deciden, es más una construcción teórica que una realidad histórica. La Confederación de Estados Independientes (CEI) que sustituyó a la Unión Soviética no ha operado como unidad política y la Confederación Helvética, a pesar de su nombre, no reconoce el derecho de secesión de sus cantones. De hecho, en 1847 Suiza sufrió una guerra civil en la que siete cantones del sur se quisieron separar de la Confederación y los otros 15 cantones se lo impidieron, lo que no fue obstáculo para que se mantuviera el nombre oficial de Confederación Helvética, que se ratificó en la Constitución de 1848, que en realidad conformaba un Estado federal.

De modo que de los tres tipos de Estado: unitario, federal y confederal, en la realidad solo se encuentran los Estados unitarios y los federales. Normalmente, el Estado unitario suele estar centralizado, mientras que el Estado federal suele estar descentralizado porque los Estados, que así se llaman en los Estados Unidos de América, los landers, como se les denomina en la República Federal de Alemania, o los cantones de Suiza, aunque han perdido la soberanía, que desde su integración en la Federación pasa a la totalidad de ella, mantienen muchas de sus antiguas competencias.

\section{§5. LA PARADOJA ESPAÑOLA}

El caso del reino de España es paradójico porque a partir de un Estado unitario, conforme se define en su Constitución al afirmar textualmente que la "soberanía reside en el pueblo español", en su conjunto, se ha conformado un Estado autonómico muy descentralizado, en algunos aspectos más que algún Estado federal. 
No obstante, han sido necesarias varias sentencias del Tribunal Constitucional ${ }^{16}$ para dejar claros dos conceptos jurídicos: que en España solo hay una nación, y que la soberanía reside en el pueblo español en su conjunto. El artículo 1.2 dice textualmente: "La soberanía nacional reside en el pueblo español, del que emanan los poderes del Estado". Lo que significa que la Constitución de 1978 utiliza el término nación conforme a la concepción francesa de Sieyès y Renan, que -por otra parte- es el concepto que rige en el Derecho Internacional, a pesar de que la injerencia internacional es cada vez mayor en los Estados, especialmente en los pequeños, pero si a la presión exterior la denominamos injerencia internacional es precisamente porque se ejerce sobre naciones soberanas.

Las tensiones secesionistas que hay en España exige la mayor exigencia terminológica porque contribuye a formular los debates políticos de un modo más riguroso, sin embargo, ocurre todo lo contrario. Cualquiera puede hacer uso del concepto nación o nacional, aunque sea para referirse a una región o a una institución de esa región. Y ya tenemos otro concepto: región. Está establecida en la disciplina académica que llamamos geografía que la nación, es decir el territorio poblado bajo las fronteras de un Estado, es el todo; y la región, una parte. De hecho, las comunidades autónomas son geográficamente "regiones" aunque esa palabra quedara devaluada en el artículo 2 de la Constitución española de 1978 al establecer lo siguiente:

La Constitución se fundamenta en la indisoluble unidad de la Nación española, patria común e indivisible de todos los españoles, y reconoce y garantiza el derecho a la autonomía de las nacionalidades y regiones que la integran y la solidaridad entre todas ellas.

Obsérvese que este artículo dice claramente que la unidad de la nación española es anterior a la propia Constitución porque este cuerpo legal "se fundamenta" en la indisoluble unidad de la Nación española. Por otra parte, distingue a la hora de reconocer y garantizar el derecho a la autonomía entre "nacionalidades y regiones", sin aclarar la diferencia entre unas y otras. De hecho, conforme se aprobaban los estatutos de autonomía por el Congreso de

${ }^{16}$ Sentencia del Tribunal Constitucional 31/2010, de 28 de junio de 2010 (BOE de 16 de julio de 2010), y STC 136/2018, de 13 de diciembre de 2018 (BOE de 15 de enero de 2019). 
los Diputados, coherentemente con el concepto de soberanía nacional de un Estado Unitario que optaba por ser descentralizado, se observaba que en casi todos ellos preferían definir a la comunidad autónoma como "nacionalidad", pero las que se han definido como "región" han comprobado que no existe ninguna consecuencia jurídica entre usar una palabra u otra ${ }^{17}$.

Es preciso resaltar que durante la II República, tan laxa en otras cuestiones, se cuidara mucho la terminología en relación con la palabra "nación" y "nacional", hasta el punto de prohibir el uso de la palabra "nacional" a todo aquello que no lo fuera. El Decreto de 21 de abril de 1932 disponía expresamente en su artículo único:

A partir de la publicación de la presente disposición, las Sociedades, Asociaciones y Entidades de todo género y los particulares no podrán usar en sus títulos, denominaciones y actuación el calificativo "nacional" sin expresa autorización, en su caso, del Consejo de Ministros ${ }^{18}$.

La tensión conceptual entre el significado de la palabra "nación" que se debe a la teoría política francesa y la que proponía la filosofía alemana ha quedado bastante superada en el ámbito jurídico internacional, aunque todavía hay países, como en España, donde a pesar de los antecedentes de la II República, la desproporcionada influencia actual de los nacionalismos periféricos ha propiciado una confusión conceptual que se vislumbraba en la Constitución española de 1978 y que se puso de manifiesto en el debate parlamentario del último Estatuto de Autonomía de Cataluña, en especial al pretender definir esa comunidad autónoma como una nación ${ }^{19}$.

${ }^{17} \mathrm{Si}$ bien es cierto que, en la improvisación del proceso autonómico, se privilegió en un primer momento a tres territorios, a los que se llamó "nacionalidades históricas", tras el fracaso de la aprobación del Estatuto de Andalucía, porque en la provincia de Almería se votó que no, el presidente Suárez, con su famosa expresión "Café para todos", abrió la puerta a unas comunidades autónomas en las que todas ellas competían por tener las mayores competencias posibles, se llamaran "nacionalidades" o "regiones". Muy pocos juristas se pronunciaron al respecto; sí lo hizo el catedrático de Derecho Constitucional Juan Ferrando Badía (1926-2007), que no aceptó el contenido semántico peyorativo que se pretendía dar a la palabra región, de modo que escribió varias obras en que utilizaba esa palabra, por ejemplo, en su libro de 1978 El estado unitario, el federal y el estado regional (Madrid: Tecnos).

${ }^{18}$ Gaceta de Madrid del 22 de abril de 1932.

${ }^{19}$ En el preámbulo del Estatuto de Autonomía catalán último se afirmaba, a partir de la tergiversación del concepto "nacionalidad", que Cataluña era una "nación", lo que el Tribunal Constitucional advirtió y declaró inconstitucional (STC 31/2010, de 28 de junio de 2010. BOE 16 de julio de 2010).

SCIO. Revista de Filosofia, n. ${ }^{\circ} 20$, Julio de 2021, 185-216, ISSN: 1887-9853 


\section{§6. NACIÓN Y PATRIA}

La teoría política sobre la palabra nación ya se ha tratado, ahora procede comentar el concepto de patria que el Diccionario de la RAE define como el lugar, ciudad o país en el que se ha nacido. Es cierto que también da el siguiente significado: "Tierra natal o adoptiva ordenada como nación a la que se siente ligado el ser humano por vínculos jurídicos, históricos y afectivos", en esta segunda definición la patria y la nación coincidirían, pero hay una gran diferencia entre ambos conceptos, y por eso hay que insistir en el primer significado. El concepto de patria es concéntrico e integrador; el concepto nación no puede serlo porque en términos jurídicos exige ser depositario de soberanía, de ahí que sea excluyente y no concéntrico, y no se dice en sentido peyorativo sino puramente descriptivo. No cabe la pertenencia a dos naciones porque solo se pertenece a la nación cuyo pueblo ostenta la soberanía que se manifiesta en su constitución como Estado. En consecuencia, no es posible una nación de naciones ${ }^{20}$. Podrá haber una nación de antiguas naciones, y esto se observa muy fácilmente en la formación de Estados federales, pero cuando surge la nueva nación las demás dejan de serlo. Son regiones porque la nación es el todo y la región, la parte. En el proceso de construcción europea la aplicación práctica de esta teoría se confirma: de momento tenemos la Europa de las naciones porque las decisiones soberanas las adoptan cada una de ellas.

${ }^{20}$ I. Fernández Sarasola (2019). La Constitución Española en cien preguntas. Madrid: Nowtilus. En este libro se defiende la idea que no aparece en la Constitución de la que trata, de que puede haber una "nación de naciones", siempre que la nación fuera "nación política" y las naciones, "naciones culturales". Es un ejemplo más de los reiterados e ingenuos intentos de aplacar las tensiones secesionistas con imprecisiones verbales, que lo único que han conseguido es, además de no aplacarlas, crear mayor confusión en la terminología, pues palabras con un significado claro pueden acabar convirtiéndose en conceptos jurídicamente indeterminados, incluso en grave contradicción con los conceptos consolidados internacionalmente. El principal antecedente institucional del uso de "nación de naciones" lo encontramos en la obra colectiva J. Álvarez Junco et al. (2005). El nombre de la cosa. Debate sobre el término nación y otros conceptos relacionados. Madrid: Centro de Estudios Políticos y Constitucionales, 96 y 112, donde se afirma que "en estos terrenos los conceptos son ambiguos", lo que no es cierto. Aunque se presenten 14 definiciones de la palabra nación, su significado es uno y claro en la ONU y en el derecho internacional, así que ¿por qué no tiene que serlo en las obras de ciencias sociales que se publican en España? Sería preferible dejar sentado que cualquier significado que no sea el reconocido por la ONU, además de no ser operativo jurídicamente, es una equivocación o una tergiversación, cuando no una manipulación del concepto. Así se contribuiría a aclarar los debates sobre esta cuestión. 
No hay una nación europea, todavía, sino naciones que aceptan la convergencia que supone la aprobación de tratados, por lo que en ocasiones convocan a sus ciudadanos a referéndum. Esto no quiere decir que no vaya a haber una nación europea en el futuro: la habrá cuando todo el pueblo europeo en su conjunto sea soberano, y todo apunta a que, de llegarse a ello, lo será por la vía de la federación de las actuales naciones, que dejarían de serlo.

Todo este proceso también tiene relación con que el concepto de patria, al no estar vinculado al concepto de soberanía, sirve para todos los niveles de organización política. El siguiente ejemplo también fue expuesto hace unos años y ahora es preciso retomarlo: cualquier valenciano sabe que el municipio donde nació es su "patria chica", patria que no entra en contradicción con la "patria valenciana", conforme la denomina el himno a la Virgen de los Desamparados. La patria chica y la patria valenciana no entran en contradicción, tampoco, con la patria española, e incluso se puede afirmar, con completa corrección en la terminología politológica, mi "patria europea" o mi "patria es el mundo". Porque el concepto patria encierra la relación de afecto con el respectivo "pueblo" o "colectividad" a distintos niveles (Martínez Roda, 2017: 337), y por seguir con el ejemplo: la localidad de nacimiento o patria chica, la comunidad autónoma o patria valenciana, el reino de España o patria española, la patria europea o el mundo entero, es decir, la humanidad. No obstante, como dice Ginés Marco, "este es un buen momento para recordar que hay algunas formas apasionadas de lealtad al país que no se conciben como patriotismo" (Marco, 2020: 163), porque niegan su carácter concéntrico e integrador. En general, el pensamiento nacionalista rechaza la posibilidad de distintas adscripciones colectivas por su confusión de los conceptos de patria y nación, porque no conciben una pluralidad de lo que llaman "identidades" (Reinares, 2001: 51).

En contra de lo que suele mantener el pensamiento nacionalista, es posible la adscripción afectiva en distintos niveles colectivos, como se ha visto, porque la palabra patria no va acompañada de soberanía. La soberanía, entendida como la formuló Bodino, como poder originario no sujeto a ningún otro poder, exige determinar quién es el depositario de esa soberanía. El pueblo o colectividad que ejerza la soberanía es una nación. Un pueblo que no tiene soberanía no es una nación por mucho que se pretenda retorcer el idioma y se 
hagan los circunloquios que se quieran para que lo parezca. Pero el problema está vivo en el uso intencionado del lenguaje, por lo que al observar la gran discrepancia conceptual sobre la palabra nación provocada por quienes usan ese término para referirse a una colectividad, a un pueblo si se quiere, aunque no exista como nación soberana y, además, en ocasiones, la supuesta nación no sea ni siquiera un pueblo real sino simplemente la delimitación de un grupo humano por el nacionalista de turno, Ferrando Badía se preguntaba cómo resolver "el problema que se presenta al tener que decidir si cabe aceptar un criterio como carácter exclusivo o si todos ellos son legítimos" (Ferrando, 1975: 21). No obstante, se puede afirmar que esta aparente disyuntiva, en realidad, se resuelve con la observación de que es una "falsa polisemia" (Martínez-Echevarría, 2015: 440) que no cabe en el derecho. Por ejemplo, Agirreazkuenaga (2014: 31) afirma que "el modelo del Estado-nación inventado en Europa fue exportado al resto de los continentes, de manera que dicho modelo es el instrumento por antonomasia sancionado como básico en la Organización de Naciones Unidas", para, a continuación, después de este concepto claro e indiscutible, oscurecerlo al afirmar que la nación "es una organización simbólica de un grupo humano" (2014: 31).

La Organización de Naciones Unidas, como es lógico en derecho, necesita utilizar un concepto inequívoco de nación, con carácter exclusivo, porque el serlo o no determina la posibilidad de ingresar como miembro. Y por supuesto, desde su creación, optaron sus fundadores por el concepto surgido en Francia de que una nación es un pueblo, asentado en un territorio bajo la forma política de Estado. Y sin Estado no se puede ingresar en la ONU, así lo dice el artículo 4 de la Carta fundacional aprobada por los 51 primeros miembros:

Podrán ser Miembros de las Naciones Unidas todos los demás Estados amantes de la paz que acepten las obligaciones consignadas en esta Carta, y que, a juicio de la Organización, estén capacitados para cumplir dichas obligaciones y se hallen dispuestos a hacerlo.

La confusión conceptual al utilizar la palabra nación se acentúa cuando un grupo social es convencido de que debe "construir una nación", y ese convencimiento parte de la idea de que esa nación ya existe, cuando nunca es cierto; de ahí la necesidad de retorcer el lenguaje para llamar nación a lo que 
no lo es ${ }^{21}$. Los éxitos de las unificaciones de Alemania e Italia en el siglo XIX y toda la pléyade de escritores nacionalistas contribuyeron a que se empleara la terminología nacional antes de la existencia de la nación, al igual que ocurre actualmente en los territorios donde existen movimientos nacionalistas. Estos utilizan la terminología nacional a sabiendas de que no corresponde con la verdad, por lo que Francisco Murillo (1918-2004) ha señalado la paradoja de que existan movimientos de "nacionalistas sin nación", lo que indica que intencionadamente "se han divorciado los términos nacionalista y nación" (Murillo, 1972: 173). Los nacionalistas que promueven la creación de una nación hablan de ella como si existiera; más todavía, procuran hacerla anterior a la nación de la que real y efectivamente forman parte.

En cualquier caso, también queda claro que el sentimiento de afecto hacia la colectividad a la que se pertenece, el patriotismo, no debe confundirse con el nacionalismo. "El sentido de pertenencia (lo que Isaiah Berlin, con intención de señalar la diferencia, ha calificado alguna vez como «patriotismo») es fundamental para el ser humano" (Tutor de Ureta, 2009: 229), por lo que con claridad de ideas hay que evitar que el nacionalismo se aproveche de él; para ello "hablar del nacionalismo en clave política permite objetivarlo, separándolo del afecto personal a la nación" (Andrés-Gallego, 2008: 654).

Esta breve reflexión sobre el futuro de Europa puede resultar aclaratoria de los conceptos que se están barajando en este estudio: cabe pensar que el gran reto de futuro del "Viejo Continente" es la unión de Europa; para ello es necesario el patriotismo que ligará a los europeos por "vínculos jurídicos, históricos y afectivos", y por ello, cuando se haya producido la transferencia de soberanía a la totalidad del "pueblo europeo", sus ciudadanos no dejarán de tener los vínculos de sus antiguas naciones, aunque se haya constituido una nación europea; de ese modo se habrá creado una nueva nación sin nacionalismo, pero con los "vínculos afectivos" entre sus habitantes que se

${ }^{21}$ Un ejemplo de esto lo encontramos en el artículo de J. Arregi Orue (2014). "El programa 'Resilient Nations' de la ONU: algunas claves para la continuidad de las minorías nacionales". Naciones en el Estado-Nación: la formación cultural y política de las naciones en la Europa contemporánea (pp. 113-122). Barcelona: Editorial Base. Utiliza en el título el concepto minoría nacional, mientras que en el lenguaje de la ONU se habla de IP (pueblos indígenas). Esta es otra técnica de oscurecimiento que se combina con la falacia de la resbaladiza pendiente terminológica. 
denomina patriotismo. De la cesión de soberanía o de su traspaso de un sujeto soberano a otro no se puede inferir que la "soberanía sea un principio que se derrumba" 22 , al contrario, se encuentra plenamente operativo, como se acaba se exponer, y con la salida del Reino Unido de la Unión Europea ha quedado demostrado. El Reino Unido en virtud de su soberanía ha decidido, con un referéndum, abandonar la Unión Europea.

\section{§7. El esquema kuhntiano de Reyes Pascual y la inVención DE LA IDENTIDAD COLECTIVA}

El "nacionalismo sin nación" ha seguido a Fichte en mayor o menor medida, aun sin citarlo expresamente, es decir, ha querido construir la nación a partir de rasgos culturales, étnicos o lingüísticos, según el caso, aunque previamente no existiera. Este fenómeno es al que Reyes Pascual ha aplicado el esquema kuhntiano porque resulta útil, no tanto para explicar el contenido del nacionalismo como para analizar las distintas formas de desarrollo de las teorías sobre el nacionalismo y su influencia desde principios del siglo XIX hasta la actualidad (Reyes, 2019). Isidro Sepúlveda afirma que no hay un solo nacionalismo sino diversos, lo que es cierto (Sepúlveda, 1996: 315). También se podría decir, a modo de ejemplo comparativo con otras ideologías, que no hay un solo socialismo sino varios, lo que también es cierto; pero no es menos cierto que todos los socialismos tienen un tronco común. Lo mismo ocurre con el nacionalismo, aunque se ha manifestado de forma camaleónica, pues el socialismo siempre ha quedado adscrito a la izquierda del espectro ideológico, mientras que ha habido nacionalismos tanto a la derecha como a la izquierda del panorama político, eso sí, casi siempre en su versión extrema ${ }^{23}$. De ahí que

${ }^{22}$ R. Bergalli, E. Resta (1996). Soberanía, un principio que se derrumba: Aspectos metodológicos y jurídico-políticos. Barcelona: Paidós. Es preciso afirmar que el título no corresponde con el contenido, pues se trata de una obra en que varios autores analizan los cambios que se producen en la aplicación de la soberanía en un mundo tecnológico y globalizado, y a lo largo de los capítulos no se observa un derrumbamiento como dice el título, sino una adaptación.

${ }^{23}$ No es necesario tener unos grandes conocimientos del pasado para saber que tanto el fascismo como el nazismo tuvieron una adscripción de extrema derecha, mientras que el FLN de Argelia o ETA la tuvieron de extrema izquierda, por poner solo unos ejemplos obvios entre tantos otros. 
se pueda decir que, aunque ha habido diversas formas de nacionalismo, incluso que dicha palabra tiene diversas acepciones (Andrés-Gallego, 2012: 14), no es menos cierto que en su tronco común coinciden en el intento de crear un estado a partir de una nación inexistente previamente, cohesionando a un grupo social capaz de asumir la construcción ideológica de la "nueva nación" $\mathrm{y}$, en las naciones ya creadas, en un afán expansivo sorteando las normas del derecho internacional, cuando no infringiéndolas abiertamente.

Por otra parte, independientemente de la gran multiplicidad existente de explicaciones sobre el nacionalismo y sus efectos, la clave de su funcionamiento se encuentra en que, en contra de lo que suelen afirmar los nacionalistas que creen que sus "naciones", reales o supuestas, son "esencias", la realidad histórica muestra que las naciones no tienen esencia sino mera existencia; porque las identidades de las naciones no son "más que un constructo: un símbolo que expresa la expectativa de cohesión comunitaria en concurrencia con otras comunidades" (Andrés-Gallego, 2008: 299), y así lo ha puesto de manifiesto Anderson, al afirmar que son construcciones sociales en las que se establecen "lealtades para cimentarlas" 24 . Lo que ha ocurrido en el pasado es que ha habido naciones que surgieron de anteriores reinos donde la unidad ya estaba establecida; en esos casos, la "construcción social" resultaba bastante clara, al igual que las "lealtades para cimentarla", pues ya venían de mucho tiempo atrás. El problema de hecho surge cuando la "construcción social" es de una nación que no existe ${ }^{25}$, ahí comienza el "todo vale" para encontrar las "lealtades para cimentarla", incluso la irracionalidad" en el pensamiento y en la acción, para captar voluntades y acallar a los que no se suman al proyecto, con actos tan contradictorios como "la fiesta y la violencia más extrema" (Andrés-Gallego, 2008: 82). En naciones de grandes dimensiones se aprecia claramente, como en el Reino Unido. Su sistema político, al ser

${ }^{24}$ B. Anderson (1991). Imagined Communities: Reflections on the Origin and Spread of Nationalism (2. ${ }^{a}$ ed.). Londres/Nueva York: Verso. Está traducido en 2011 con el título Comunidades Imaginadas. México: Fondo de Cultura Económica.

${ }^{25}$ J. Espinosa Antón (2000). El reconocimiento político de la identidad cultural (o del tejido multicultural) nacional. En Nacionalismo: pasado, presente, futuro. Cuenca: Ediciones de la Universidad de Castilla-La Mancha.

${ }^{26}$ M. Weber (1992). El problema de la irracionalidad en las ciencias sociales. Estudio preliminar de J. M. García Blanco. Madrid: Tecnos 
democrático, permite el cultivo de identidades colectivas que no necesariamente coinciden con el proyecto nacional, incluso en ocasiones se oponen a él: la "identidad irlandesa" logró crear una nación, ahora lo pretenden el nacionalismo escocés, incluso el galés; pero esto no quiere decir que el Reino Unido haya dejado de ser una nación (Colley, 1992: 374-375), lo que sí quiere decir es que la cultura política democrática se ve muy afectada, como ocurre también en determinadas regiones francesas o españolas, donde se plantean "identidades" que se presentan en confrontación con la nación existente. En cualquier caso, una nación no tiene por qué corresponder a una "identidad colectiva". Si corresponde a una serie de características comunes, bien; pero si no corresponde, también. La nación es solo, y nada menos, una unidad política en la que su población vive en un territorio gobernado por un Estado. Cuanta mayor identificación con las instituciones y con el proyecto político haya entre sus miembros, mayor cohesión; pero una nación sin características comunes, como la Confederación Helvética, multiétnica y multilingüistica, y también las naciones americanas o las africanas, son tan nación como la más identitaria. La nación no requiere "identidad", sino soberanía; en definitiva, como han expresado acertadamente Bas Leijssenaar y Neil Walker, la nación es la soberanía en acción y precisamente el concepto de soberanía es imprescindible para entender los problemas de hoy ${ }^{27}$. Con este concepto quedan en evidencia las paradojas que Juan García ha señalado en relación con las "identidades nacionales" (García, 1994: 166), que por otra parte -como se ha dicho-Anderson demuestra que son meras construcciones sociales que buscan cimentar lealtades; de ahí que puedan tener algún interés desde el punto de vista de la psicología social, pero no desde el punto de vista jurídico, ya que todas las constituciones establecen en qué sujeto colectivo recae la soberanía, pues ese sujeto es la nación (Reyes, 2019: 3).

De ahí que no sea del todo cierta la afirmación de Özkirimli cuando considera que "la nación es producto del nacionalismo" (Özkirimli, 2010). No siempre. De hecho, como ya se ha expuesto anteriormente, las primeras naciones surgieron de la sustitución de la soberanía real por la soberanía nacional,

${ }^{27}$ B. Leijssenaar, N. Walker (Eds.) (2019). Sovereignty in action. Cambridge: Cambridge University Press, 6. Conviene recordar que profesan en las universidades de Lovaina y Edimburgo, respectivamente, es decir, en Bélgica y Escocia, dos territorios con graves tensiones nacionalistas. 
sin nacionalismo previo. Por ejemplo, antes de la Constitución de 1812 que define por primera vez a la nación española, "no hay nacionalismo español" (Andrés-Gallego, 2008: 542), hay un patriotismo muy arraigado que llevó a levantamientos populares y resistencia a la invasión napoleónica, pero no hay nacionalismo propiamente dicho. Precisamente el primer nacionalismo surge en Alemania, donde no existía una corona aglutinadora previa a la nación, como en Francia, España, Dinamarca, Holanda o Suecia; allí la nación sí fue producto del nacionalismo, aunque finalmente se vehiculizara a través de la hegemonía del reino de Prusia.

\section{§8. NACIONALISMO DEL SIGLO XXI Y MARKETING}

Para que la nación sea un producto del nacionalismo, como pretenden los diferentes separatismos presentes en Europa, el marketing político es una herramienta muy utilizada. También el sistema educativo, pero el marketing tiene la doble ventaja de que no necesita reclutar a miles de profesores con la misión unidireccional de crear la nación, y de que los medios de comunicación de masas y las redes sociales, donde se aplican los principios del marketing, se muestran mucho más influyentes que la docencia establecida, en franca decadencia como influencer.

Ahí entra en escena el marketing político con toda intensidad, con el objetivo de conseguir convencer a ese pueblo o colectividad, como ya hicieron Fichte y los primeros nacionalistas alemanes, de que existía una nación, aunque no hubiera Estado. Y se utilizó principalmente la educación. Y aquí surgen otras cuestiones que sobrepasan este estudio: ¿es moral falsear a sabiendas el pasado para conseguir los objetivos políticos nacionalistas? ${ }^{28}$. ¿Es moral el dirigismo docente hacia esos mismos objetivos políticos en clases para menores de edad?, y muchas otras cuestiones que se plantean cuando la educación no tiene como objetivo formar a los estudiantes, sino conseguir su

${ }^{28}$ F. Ovejero Lucas (2006). Nacionalismo: del mito a la moral. Revista de libros 118, 8. En esta página escribe lo siguiente: "La historia no asegura cimientos al nacionalismo. No los proporciona (...) porque los hechos, a palo seco, no justifican los proyectos políticos, las soberanías o los derechos colectivos". 
militancia. En realidad, ha habido muchos ejemplos, y no solo nacionalistas, en que se ha conseguido con éxito la militancia e, incluso, el reclutamiento de los estudiantes, lo que no quiere decir que sea algo positivo y decente.

Sin embargo, para el marketing no existen esas preocupaciones. Según sus teóricos, a la hora de vender, sea un producto o una idea, "no existe la realidad objetiva. No hay hechos. No hay mejores productos. Lo único que existe en el mundo del marketing son percepciones en las mentes de los clientes actuales y potenciales. La percepción es la realidad" (Ries y Trout, 2003: 23). De este modo, para nada sirve ni la antropología, ni la sociología, ni la lingüística y, por supuesto, ni la historia ni la filosofía. La única meta consiste en que la "nación imaginada", generalmente presentada como víctima, logre hacerse creíble a través de la raza, de la lengua o de cualquier otra característica aglutinadora y así conseguir que el pueblo que debe conseguirla o extenderla, perciba que forma parte de ella y comparte los elementos de su "identidad", de este modo las "lealtades para cimentarla" surten efecto. Y así siempre, desde Fichte a Milosevic, pasando por De Valera y tantos otros, sin olvidar a Hitler y Mussolini. En definitiva, el marketing con el que se impone una "identidad nacional" o se expande es "un juego disputado en la mente del cliente potencial, necesita dinero para introducirse en la mente, y una vez está allí, dinero para permanecer en ella" (Ries y Trout, 2003: 143), y para ello se ha utilizado y se utiliza mucho dinero público.

La imposición de una "identidad" con todos los medios de persuasión del mundo contemporáneo ha afectado a los fundamentos de los Estados democráticos que se convirtieron en Estados culturalmente dirigistas, de ahí la importancia que da el nacionalismo al control del sistema educativo y a las técnicas del marketing. No obstante, el control de las mentes, mediante la correspondiente creación de ministerios de "cultura", no afectó solo a países gobernados por nacionalistas, sino también a los comunistas que utilizaron técnicas de propaganda muy similares ${ }^{29}$. Gustavo Bueno (1924-2016) ha explicado cómo se produjo este proceso:

${ }^{29}$ A. Pizarroso Quintero (1990). Historia de la propaganda: notas para un estudio de la propaganda política y de "guerra". Madrid: Eudema Universidad. 
La idea política del "Estado de la cultura", inventado por Fichte, según el cual, la misión del Estado era no ya mantener el orden entre los ciudadanos (el Estado gendarme), ni tampoco velar por la satisfacción de las necesidades basales (Estado de Bienestar), sino garantizar el sostenimiento y promoción de la cultura de cada pueblo, en tanto Estado de Cultura. A cada pueblo o a cada Nación, con una cultura propia, se le reconoce "el derecho y el deber" de constituirse como Estado político soberano. Acogiéndose a este principio (reformulado ya en el siglo xIx por Pascual Mancini como Cogito ergo sum de la ciencia política) muchos pueblos o naciones étnicas reivindicaron sus culturas nativas, juntamente con la reivindicación de un Estado político propio (...) En los siglos Xx y xxI este proceso de reivindicación política resurgió en la forma de nacionalismos fraccionarios (Bueno, 2016: 160).

\section{§9. El Estado Actual DE La CUESTIÓN}

Como consecuencia de la importancia que ha tenido el nacionalismo en los dos últimos siglos, ha sido un fenómeno muy estudiado; se podría decir que muy bien estudiado en la segunda mitad del siglo xx por autores tan acreditados como Carlton J. Hayes (1882-1964), Hans Kohn (1891-1971), Benjamín Akzin (1904-1985), Kenneth R. Minogué (1930-2013), Elie Kedourie (1926-1992), Robert Lafont (1923-2009), Benedict Anderson (1936-2015), Jurgen Habermas e Isaiah Berlin (1909-1997) ${ }^{30}$. En España, en general ha habido más interés por el estudio de la "nacionalización" del pueblo español que por el nacionalismo en general ${ }^{31}$, no obstante, también ha habido estudios históricos que se centraron principalmente en el "nacionalismo periférico"

\footnotetext{
${ }^{30}$ Todos los citados se pueden considerar verdaderos clásicos en el estudio del nacionalismo, cuyas obras traducidas se recogen en la bibliografía.

${ }^{31}$ W. L. Bernecker (2016). Nación, nacionalismo y nacionalización en España: el debate continúa. Iberoamericana XVI(61), 267-280. Disponible en: <http://dx.doi.org/10.18441/ibam.16.2016.61>.
} 
español $^{32}$, incluso en forma de novela ${ }^{33}$, lo que permite profundizar en alguna de sus características, como, en este caso, el victimismo.

En resumen, los trabajos sobre el nacionalismo en todo el mundo han llegado a ser tan abundantes que incluso se ha publicado el mencionado estudio en el que se aplica el esquema kuhntiano para intentar dar coherencia explicativa al debate en torno al nacionalismo a principios del siglo XXI, solución muy adecuada, pues, en muchas ocasiones, como advirtió Minogué, "el estudio de la ideología ha sido adulterado por la ideología". En 2019, ha aparecido otro artículo de Reyes Pascual en el que, a modo de síntesis sobre el nacionalismo, se analizan las aportaciones de la siguiente generación de los anteriormente mencionados que, además, amplían el abanico de procedencias y de disciplinas, pues se aborda el nacionalismo no solo desde una perspectiva histórica o filosófica, como los anteriores, sino también desde la psicológica social, la sociológica y la politológica, como han hecho Beiner, Anthony Giddens, Hobsbawm, Leijssenaar, Özkirimli, Roger, Anthony Smith, Spenser, Walker, Wollman y otros investigadores. Continúan con el estudio de los aspectos más sobresalientes de lo que "la doctrina entiende como una de las controversias más importantes de la Era Contemporánea” (Reyes, 2019: 2). Y precisamente en A. Smith "se pueden encontrar cuatro paradigmas clásicos del nacionalismo (modernismo, perennialismo, primordialismo, y etnosimbolismo) que han surgido para explicar el nacionalismo y la nación” (Reyes, 2019: 8).

No obstante, la existencia de una controversia no quiere decir necesariamente que se trate de un tema de gran trascendencia filosófica o de profundidad en sus planteamientos. Incluso para Karl Popper (1902-1994) sucede lo contrario, porque según afirma "el nacionalismo es lo más parecido a una revuelta contra la razón” (Popper, 2010: 392). Como dice Sanmartín, "lo bien cierto es que estas aserciones que mantienen ocupados a buena parte de los filósofos actúan como verdaderos distractores de cuestiones graves y carecen, a menudo, de cualquier tipo de fundamento" (2018: 55). En realidad, "todos ellos nacieron del mito, de 'memorias históricas' recreadas que, a poco que

${ }^{32}$ J. L. de la Granja Sanz (1994). La invención de la historia. Nación, mitos e historia en el pensamiento del nacionalismo vasco. En J. Beramendi, R. Maiz, M. Núñez, Nationalism in Europe. Past and Present.(pp. 97-139) Santiago de Compostela: Universidad de Santiago (II).

${ }_{33}^{3}$ J. Juaristi (1999). El bucle melancólico. Historias de nacionalistas vascos. Madrid: Espasa-Calpe. 
se escarba, se derrumban" (Ovejero, 2006: 8). Afirmación que comparte Fernando Savater, que utiliza la misma palabra, el "mito" (Savater, 1996), es decir una expresión anterior al "logos", por lo tanto, anterior al surgimiento de la filosofía y, en consecuencia, del pensamiento racional. Robert Lafont ha agrupado esta mitología del nacionalismo en tres "concentraciones míticas": el falseamiento del pasado para justificar la existencia de la realidad nacional, el anclaje territorial a partir de la confusión autoritaria de fronteras étnicas o lingüísticas con fronteras políticas y la sobreestimación de la propia tradición, real o imaginaria (Lafont, 1993). "Concentraciones míticas" que Cardells ha analizado en relación con los imaginarios colectivos que se promueven en las actuales comunidades autónomas españolas (Cardells, 2019). Este fenómeno de creación de mitos colectivos propios como "nacionales" tuvo su máximo apogeo en Europa durante el siglo XIX, pero ahora, en la España autonómica, conforme han demostrado Cardells y Pérez Garzón, forma un frente ideológico reivindicativo vinculado a sus respectivas "identidades", hasta el punto de que se modifica el pasado para presentarlo "a la carta", es decir, "usan la historia para justificar una determinada política” (Pérez Garzón, 2017: 107).

También se debe observar que la actualidad de un tema no siempre significa que se aporten nuevas cuestiones. De hecho, la ideología nacionalista es reiterativa y machacona. En palabras de Contreras, "la innegable eficacia movilizadora del nacionalismo en cuanto ideología de masas contrasta con su sorprendente indigencia teórica, con la vulnerabilidad filosófica de sus postulados, los cuales difícilmente resisten un escrutinio exigente" (Contreras, 2002: 270). Además, ya se ha visto, promueve "un mito oscurantista y confusionario" (Bueno, 2016: 60) y distrae la atención de temas verdaderamente importantes (Sanmartín, 2018: 55). Entonces, ¿por qué hay que analizarla? La explicación más clara de por qué hay que estar atentos al nacionalismo, a pesar de su irracionalidad, de su falta de solvencia intelectual y de su escasez de moral en los métodos para imponerlo, la ha dado Isaiah Berlin que, como punto de partida, aconseja no confundir el nacionalismo con la conciencia nacional, sentimiento natural de pertenencia de los seres humanos.

En conclusión, se puede decir que el concepto nación, al haber sido oscurecido por el nacionalismo y el marketing, es preciso reafirmarlo en el ámbito filosófico-jurídico. De este modo, se contribuye a evitar los efectos nocivos 
de dicho nacionalismo en el pensamiento y en la vida política. Esta cita de autoridad de Isaiah Berlin, que subraya esta conclusión, sirve como colofón de este artículo:

El nacionalismo es sin duda la más poderosa y quizás la más destructiva fuerza de nuestro tiempo (...) Quizás la humanidad viva lo suficiente para ver el día en que el nacionalismo parezca absurdo y remoto, pero para ello deberemos entenderlo y no subestimarlo; y es que aquello que no es comprendido no puede ser controlado: domina a los hombres en lugar de ser dominado por ellos (Berlin, 2019).

\section{REFERENCIAS BIBLIOGRÁFICAS}

Agirreazkuenaga Zigorraga, J., Alonso Olea, E. (Eds.) (2014). Naciones en el Estado-Nación: la formación cultural y política de las naciones en la Europa contemporánea. Barcelona: Editorial Base.

Akzin, B. (1968). Estado y nación. México: Fondo de Cultura Económica.

Álvarez Junco, J., Requejo, F., Beramendi, J. (2005). El nombre de la cosa: debate sobre el término "nación" y otros conceptos relacionados. Madrid: Centro de Estudios Políticos y Constitucionales.

Álvarez Junco, J. (2017). Dioses útiles: naciones y nacionalismos. Barcelona: Galaxia Gutenberg.

Anderson, B. (2011). Comunidades Imaginadas. México: Fondo de Cultura Económica.

Andrés-Gallego, J. (Coord.) (2008). Diez años de reflexión sobre el nacionalismo, el estado, la nación, la soberanía y lo hispánico. Valencia: Tirant lo Blanch.

Andrés-Gallego, J. (Coord.) (2012). Nación: historia universal de una palabra. Patria, nación, estado en Europa: Política y religión: VI Simposio de ADEISE. Mendoza: Universidad Nacional de Cuyo.

Augusto Míguez, R. (2012). El nacionalismo ;Vaya timo! Torres de Elorz: Laetoli Editorial. 
Austin, J. L. (1988). Cómo hacer cosas con las palabras. Barcelona: Paidós. Beramendi, J., Maiz, R., Núñez, M. (1994). Nationalism in Europe. Past and Present, 2 vols. Santiago de Compostela: Universidad de Santiago.

Bergalli, R., Resta, E. (1996). Soberanía, un principio que se derrumba: Aspectos metodológicos y jurídico-políticos. Barcelona: Paidós.

Berlin, I. (2019) Sobre el nacionalismo. Textos escogidos, edición de Henry Hardy. Barcelona: Página Indómita.

Bernecker, W. L. (2016). Nación, nacionalismo y nacionalización en España: el debate continúa. Iberoamericana XVI(61), 267-280. Disponible en $<\mathrm{http}$ ://dx.doi.org/10.18441/ibam.16.2016.61>.

Bodino, J. (1986). Los Seis Libros de la República. Madrid: Tecnos.

Bueno, G. (2016). El mito de la cultura (10. ${ }^{\mathrm{a}}$ ed.). Oviedo: Pentalfa.

Cardells Martí, F. A. (2019). Mito y nación. Radiografía de los nacionalismos de España. Madrid: Universidad Francisco de Vitoria.

Carré de Malberg, R. (1920). Contribution à la théorie générale de l'État, 2 vol. París: CNRS Éditions. Traducida en 1998 como Teoría general del Estado. México: Fondo de Cultura Económica.

Constant, B. (1989). Escritos políticos. Madrid: Centro de Estudios Políticos y Constitucionales.

Contreras, F. J. (2002). Cinco tesis sobre el nacionalismo. Revista de Estudios Políticos 118.

Colley, L. (1992). Britons. Forging the Nation 1707-1837. New Haven: Yale University Press.

Chabod, F. (1987). La idea de nación. México: Fondo de Cultura Económica.

Châtelet, F. et al. (2006). Historia del pensamiento político. Madrid: Tecnos.

Espinosa Antón, J. (2000). El reconocimiento político de la identidad cultural (o del tejido multicultural) nacional. En Nacionalismo: pasado, presente, futuro. Cuenca: Ediciones de la Universidad de Castilla-La Mancha.

Fernández Sarasola, I. (2019). La Constitución Española en cien preguntas. Madrid: Nowtilus.

Ferrando Badía, J. (1975). La Nación. Revista de Estudios Políticos 202. 
Ferrando Badía, J. (1978). El estado unitario, el federal y el estado regional. Madrid: Tecnos.

Fichte, J. G. (2016). Discursos a la nación alemana. Madrid: Tecnos.

García García, J. (1994). Nación, identidad y paradoja: una perspectiva relacional para el estudio del nacionalismo. REIS (Revista Española de Investigaciones Sociológicas) 67.

Granja Sanz, J. L. de la (1994). La invención de la historia. Nación, mitos e historia en el pensamiento del nacionalismo vasco. En Nationalism in Europe. Past and Present (II) (pp. 97-139). Santiago de Compostela: Universidad de Santiago.

Habermas, J. (1989). Identidades nacionales y postnacionales. Madrid: Tecnos.

Herder, J. G. (1877). Sämtliche Werke, t. II. Berlín: Bernard Suphan.

Juaristi, J. (1999). El bucle melancólico. Historias de nacionalistas vascos. Madrid: Espasa-Calpe.

Kohn, H. (1960). El nacionalismo: su significación y su historia. Buenos Aires: Paidós.

Lafont, R. (1967). La Révolution regionaliste. París: Gallimard.

Lafont, R. (1993). La Nation, l'État, les Régions. París: Berg International.

Leijssenaar, B., Walker, N. (Eds.) (2019). Sovereignty in action. Cambridge: Cambridge University Press.

Mancini, P. S. (1985). Sobre la nacionalidad. Madrid: Tecnos.

Marco Perles, G. (2020). Lealtad. Valencia: Tirant-UCV.

Martínez-Echevarría y García de Dueñas, A. (2015). Sentido nacional y patología nacionalista. Tesis doctoral. Madrid: Universidad Complutense.

Martínez Roda, F. (2017). El "think tank" del valencianismo. La intelectualidad valencianista en tres siglos. Castellón de la Plana: Saralejandría Ediciones.

Minogué, K. R. (1968). Nacionalismo, Buenos Aires, Ed. Hormé.

Morin, E. (1993). El Estado-Nación. En Teorías del nacionalismo. Barcelona: Paidós. 
Murillo Ferrol, F. (1972). Estudios de Sociología Política, Madrid: Tecnos.

Özkirimli, U. (2010). Teories of Nationalism. A Critical Introduction, Londres: Palgrave MacMillan.

Ovejero Lucas, F. (2006). Nacionalismo: del mito a la moral. Revista de libros 118.

Ovejero Lucas, F. (2016). La seducción de la frontera. Nacionalismo e izquierda reaccionaria. Vilassar de Dalt (Barcelona): Montesinos.

Pabón, J. (1944). Las ideas y el sistema napoleónicos. Madrid: Instituto de Estudios Políticos.

Pérez Garzón, J. S. (2017). Evolución y rasgos de las historiografías de los nacionalismos en España. Bulletin d'Histoire Contemporaine l'Espagne 52.

Pizarroso Quintero, A. (1990). Historia de la propaganda: notas para un estudio de la propaganda política y de "guerra". Madrid: Eudema Universidad.

Popper, K. (1945). The Open Society and its Enemies (I-II). Londres: Routledge \& Kegan Paul. Traducida en 2010 como La sociedad abierta y sus enemigos. Barcelona: Paidós Ibérica.

Reinares, F. (2001). Quiénes han militado en ETA y por qué. Madrid: Taurus.

Renan, E. (1882). Qu' est-ce qu'une nation? Existen dos traducciones recomendables: ¿Qué es una nación?, con estudio preliminar de R. FernándezCarvajal (1957). Madrid: Instituto de Estudios Políticos; y, en 1987, ¿Qué es una nación? Madrid: Alianza Ed.

Reyes Pascual, G. (2019). La problemática de las definiciones en el análisis del nacionalismo y la nación desde el paradigma del modernismo. Papel político $1(24)$.

Reyes Pascual, G. (2019). Desarrollo del debate teórico en torno al nacionalismo y la nación a través del esquema kuhntiano. Arbor 794(195).

Ries, A., Trout, J. (2003). Las 22 leyes inmutables del marketing. Madrid: Mc Graw Hill.

Ruiz Ramírez, S. (1990). ¿Qué es una nación? Boletín de Información (Ministerio de Defensa) 219. 
Sáenz-Díez, J. I. et al. (1994). Síntesis de Historia del Pensamiento Político. Madrid: Ed. Actas.

Sanmartín Esplugues, J. (2018). Crítica de la razón cruel. SCIO Revista de Filosofía 15.

Savater, F. (1996). El mito nacionalista. Madrid: Alianza Editorial.

Sepúlveda Muñoz, I. (1996). La investigación del Nacionalismo: evolución, temas y metodología. Espacio, Tiempo y Forma. Serie V, tomo 9.

Sieyès, E. J.: Qu'est-ce que le Tiers état? Disponible en: <www.leboucher.com>.

Smith, A. (2000). Nationalism and Modernism. Londres: Routledge.

Tutor de Ureta, A. (2009). Tres elementos fundamentales en la idea de nacionalismo de Isaiah Berlin. Astrolabio. Revista internacional de filosofia 9.

Villacañas, J. L. (1991). Fichte y los orígenes del nacionalismo alemán moderno. Revista de Estudios Políticos 72.

Weber, M. (1992). El problema de la irracionalidad en las ciencias sociales. Estudio preliminar de J. M. García Blanco. Madrid: Tecnos. 